\title{
SYMBOLIC USE OF DOMESTIC SPACE IN THE UPPER SVANETIAN (GEORGIA) VERNACULAR HOUSE
}

\author{
G. Sousa ${ }^{1, *}$, M. Alcindor ${ }^{1}$ \\ ${ }^{1}$ CI-ESG, Escola Superior Gallaecia, Largo das Oliveiras, 4920-251 Vila Nova de Cerveira, Portugal - (goretisousa, \\ monicaalcindor)@esg.pt
}

Commission II - WG II/8

KEY WORDS: Upper Svaneti, Vernacular Architecture, Space Anthropology, Symbolic Space, Popular Religion, Gender Segregation

\begin{abstract}
:
Upper Svaneti (Georgia) is a territory in almost permanent isolation amid the Caucasus mountain range. This strategic position, along with the military nature of its settlements made its defence so effective that Svaneti served as Georgia`s safehouse, protecting its chief historical and religious relics in times of crisis. This isolation also ensured the preservation of archaic cultural traditions and ancient rituals, such as animal sacrifices, ritual shaving and blood feuds, establishing what is known as popular religion. Some of these rituals, mainly those performed by women, take place in the domestic space. This paper, developed under the scope of the 3DPast project, aims to interpret the symbolic use of space in vernacular houses of Upper Svaneti. The methodological strategy combines architectonic survey with documental analysis and brings forward an interpretation of this vernacular house from a space anthropology perspective. The traditional svanetian house (machubi), is composed of a single volume, of rough quadrangular plan. The ground floor (machub) houses, during winter, the family and the cattle, while the upper floor (darbazi) was mostly used as the family residence during warmer periods. This analysis will focus specifically on the machub, where there are traces of the symbolic use of domestic space. The machub is composed of a single space with a central fireplace. This element is the axis of segmentation of female and male spaces inside the house. The present paper will address this gender-differentiated symbolic use of the domestic space through the scope of anthropology and of the Svanetian history.
\end{abstract}

\section{INTRODUCTION}

Upper Svaneti, is a historic province in Northwestern Georgia, Situated in the highest inhabited regions of the Caucasus. Its territory and its history are deeply connected with the presence of the imposing mountain range.

The province was, for the most part of its history, condemned to almost total isolation, enabling the conservation of chief historical and religious Georgian relics brought to Upper Svaneti in times of crisis, as it was the province that offered best guaranties for safeguarding them. It also allowed the conservation of peculiar traces of archaic local culture, some going back to the Middle Ages, others possibly even further.

But the Caucasus was not always as isolated and in Antiquity. It was a territory disputed by almost all major political players for its rich mineral resources, but also for its strategic position in major commercial routs to the Black Sea. Culturally, it played a chief role in ancient Greece sacred geography, for it was the destination of the Argonauts, the place where Prometheus was chained, and housed some important mythical characters such as Medea and the Golden Fleece. In particular, the myths of Prometheus and the Golden Fleece, have such a strong connection to Upper Svaneti, that Berman, Kalandadze, Kuparadze and Rusieshvili (2011) raised the hypothesis that they may have been adapted by the Greeks when they arrived in the region, around the IV century B.C. These examples illustrate the cultural richness of Upper Svaneti where, under the cloak of orthodox Christianity, ancient myths and rituals are perpetuated to the present.
This paper addresses some of those rituals, namely the ones which take place in domestic spaces. The research here presented was developed under the scope of the 3DPast project Living \& virtual visiting European World Heritage.

This project developed under the framework of the Creative Programme, from the European Commission, by Escola Superior Gallaecia, Portugal, Universitat Politènica de València and Università degli Studi di Firenze, Italy, aims to bring to attention the value of vernacular architecture both in its tangible and intangible local know-how, the importance of preserving the fabric authenticity and integrity, especially in World Heritage sites.

Methodologically, this reflection on the symbolic use of space in Upper Svanetian vernacular architecture combines different methods such as structured observation trough architectonic survey (for the characterization of the physical space), and document analysis (for the lived and symbolic space characterization). The results of those separate analysis are then qualitatively interpreted from the perspective of space anthropology.

Furthermore, the structure of the text is based on the different interpretations of the concept of space, also known as topia, such as defined by Foucault (2008), who emphasized the inherently ideological character of space. Therefore, his perception is that space is determined by a triad (power, knowledge and space). In this sense, space is perceived in all its

\footnotetext{
* Corresponding author
} 
physicality, leaving untouched the distinction between this physical space and the mental or social space, which is the main topic addressed in this paper. The vernacular house is analysed and interpreted as one space where multiple interpretations can be exemplified: the physical space, concerning architecture; the lived space, concerning the community, and the conceptualized space, regarding its symbolic use.

According to Durkheim (1968) the symbolic systems of a community may be interpreted as a recreation of its social, political and economic systems in such a way that it can be interpreted as a product of collective elaboration, of social interdependence in a system of significance. The system described by Durkheim works through mechanisms of predominance and identification, which are represented in space.

To interpret all those concepts, we start by outlining the cultural and religious background in which all the different uses of the vernacular house can be explained.

\section{CULTURAL AND RELIGIOUS BACKGROUND}

Through the years, along with orthodox Christianity, the Svans developed what can be called a popular religion or popular Christianism (Tserediani et al., 2018), where ancient cultural traditions and rituals such as animal sacrifices, ritual shavings and blood feuds, were preserved until the present day. The first part of this paper addresses the origin and development of some of these rituals.

In the Bronze Age, the Upper Svaneti territory was occupied by the Soani, one of the many tribes that were part of Colchis, a multitribal political entity that developed a highly advanced pagan culture, which, as mentioned above, was able to inspire the dominant Greek culture.

The Soani worshipped a triad, formed by a masculine deity (the moon), a feminine one (the sun), and Kviria, who reigned over the terrestrial world (Berman et al., 2011). This ancient religious system may well be the origin of the ritual sacrifice of oxen that it is still being practiced as an offer to The Great God as part of the burial ritual of the Svan. In the Bronze Age, the bull was considered a sacred animal, for the similarities between the bull's horns and the lunar crescent and it was a valuable sacrifice offered to the lunar god (Berman et al., 2011).

Tuite (2019), was the first to address the gender-differentiated assignment of ritual spaces among the Soani, thus his work was the starting point of the present discussion. He highlights that the primitive deities are always portrayed in pairs, as a couple, a symbol of female/male duality that, as explained later in the text, is perpetuated in certain cultural and ritual aspects of the Svans. A good example is the veneration of masculine saints, such as St. George and The Archangel by men of the community, while women worship female saints such as the Virgin Mary and St. Barbara (Tserediani et al., 2018). Later in the text, it will be addressed how the same duality can be observed in the social and symbolic use of domestic space.

The Bronze Age tribes, according to Tuite (2019), interpreted this duality as the contrast between purity, symbolized by the male deity, and the bodily impurity of the female, exemplifying this reasoning by the contrast between women blood, associated with the menstrual cycle or with childbirth, considered as impure, and the ox`s, which is instead believed to be purifying.
Another duality described in Tuite`s work, this one connected with space, is the contrast between Interior and Exterior. The author explains how the Sun Goddess occupied simultaneously the Interior of the Interior and the Exterior of the Exterior (Tuite, 2019, p. 3), the first suggesting the domestic space and, the latter, the uninhabited and unreachable territory beyond the settlement. For his part, the Lunar God dwelt in the Exterior of the Interior and the Interior of the Exterior, embodied in the public space, both in and around the villages, such as the forest or pastures. Seeing that the equilibrium depends on the interaction between the couple, communication spaces had also to be defined.

The survival of this pre-Christian system of beliefs and rituals may be attributed to what Tserediani, Tuite e Bukhrashvili (2018) call popular religion. In the period of consolidation of the orthodox Christianity, between the VIII and the XIII centuries, as the noble families appropriated the religious spaces inside the villages, the peasants continued to perpetuate ancient rites, transferring them to the domestic environment or into discreet spaces in the periphery of the hamlet. Later on, during the Ottoman's domain over Georgia, the presence and influence of the orthodox clergy were severely weakened and although the Ottoman's authority didn't reach the free territory of Upper Svaneti, the priests where nonetheless expelled and the elders among the Svan communities appropriated their roles. This semi-laicization of religious practices and spaces may have, somehow, legitimized long preserved pagan rituals that could, once more, be practised openly, at least by the male elements, given that the Svan women were not allowed inside churches, they were limited to the lamaria, a space attached to the church, where they bake ritual bread, or on specific dates in the liturgical calendar, make their own rituals (Tserediani et al., 2018).

Therefore the secularization of religious spaces, could have possibly supported the consolidation of the popular Christianity, described by Freshfield (1896, p. 216) as a peculiar fusion of "church rites, Persian sun-worship, and old pagan beliefs and sacrifices".

Another possible consequence was the definition of the genderdifferentiated organization of ritual spaces, which will be detailed over the next paragraphs.

\section{THE VERNACULAR HOUSE OF UPPER SVANETI}

The analysis of the different meanings of the Upper Svanetian vernacular spaces starts with the portrayal of the most basic concept: the physical space, addressing the architecture and the organization of space that characterizes these vernacular buildings.

Traditional Svanetian houses are part of a defensive system formed by the tower, the house and the fields, with their protective fences around them. These defensive clusters are the better-known image of the Upper Svaneti cultural landscape, that have been enlisted in the World Heritage Site since 1996.

The presumed origin of these defensive systems (Figure 1) goes back to the Middle Ages (X-XIII), a time when they offered protection against possible offensives from their northern neighbours, but also against other Svan clans, when, feudalism blood feuds were established. Therefore, each family built itself a military/domestic system ensuring their auto-sufficiency. 


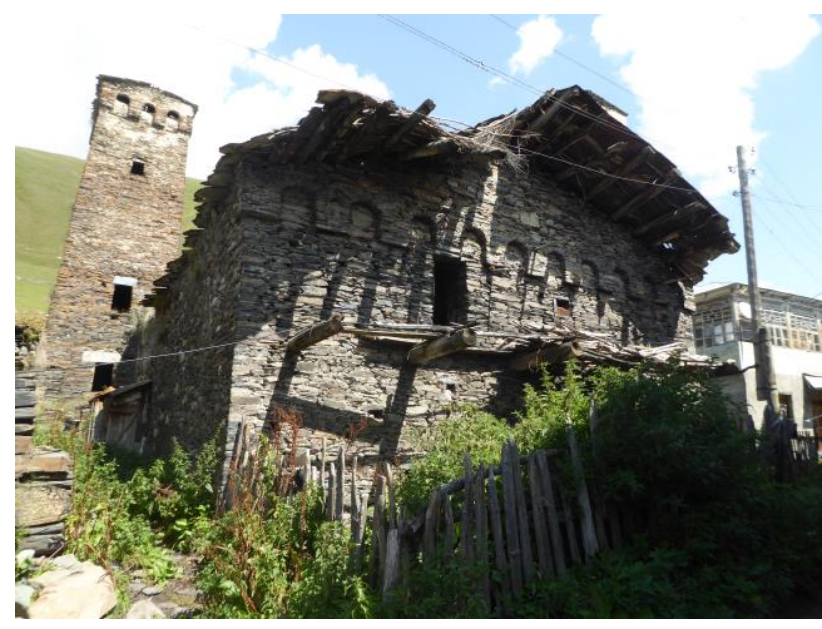

Figure 1. Domestic cluster with tower in Murkmeli, Upper Svaneti, CI-ESG, 2018.

The towers (Koshki) are imposing in the village's skyline as, according to its vigilance and signalization use, they reach considerable heights ( 3 to 5 storeys high), while the rest of the buildings blend with the landscape. They are built in local stone, mostly schist, and have a quadrangular plan configuration, which reduces in size as its elevation increases. At the top, it presents small openings for throwing projectiles (arrows, stones, etc.) to any invading force. In addition to their primary military function, they were also used as storage areas and warehouses on the upper levels.



Figure 2. Plan of Machubi 10, Chazhashi, Ushguli, CI-ESG, 2019.

The house (machubi) is usually attached to one of these towers (Figure 1) and is also composed of a single volume, with an irregular quadrangular plan (Figure 2). Its organization includes two levels, the machub and the darbazi (Figure 3).

The machub is the ground floor and the main space of the house. It is occupied during the long and harsh winters by the family and the cattle. The space organization of this floor is marked by the presence of two key elements: the fireplace, occupying the centre stage of this floor's spatial organization, and the wooden partition, where the cattle and goats are kept, and that closes the space in two or three corners.

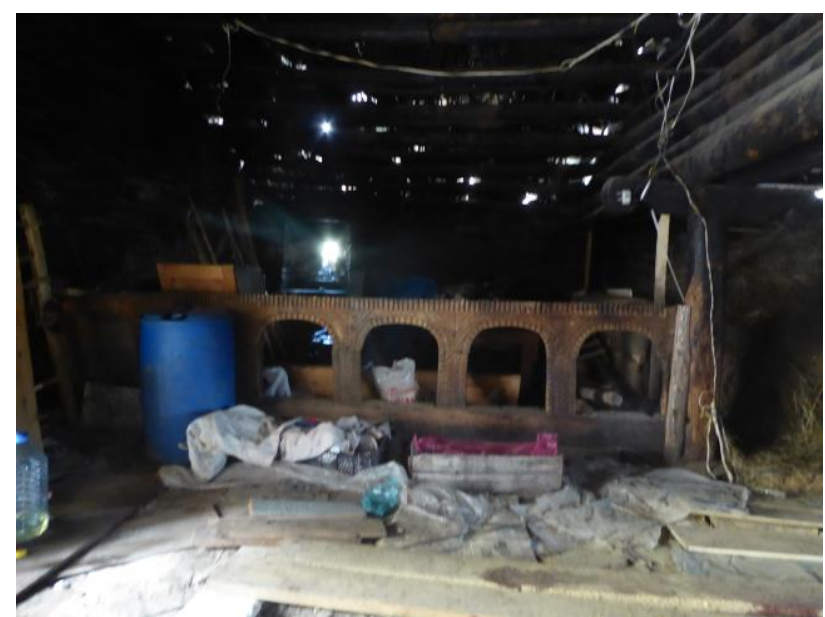

Figure 3. Wooden partition inside a machub in Zhibiani,

Upper Svaneti, CI-ESG, 2018.

Despite the presence of the fire, there are no chimneys, and the house presents very few openings, which can be interpreted as another defensive feature. The windows are rare and protected by wooden shutters, but sometimes there are none and "the light penetrating only through the interstices in the unmortared wall, while the smoke escapes through the roof" (Freshfield, 1896, p. 208).

The fireplace has an evident influence on daily habits for it ensures the preparation of meals, provides heat during harsh, long winters, and also, given the above mentioned reduced dimensions or non-existing windows, offers lighting to the otherwise dark interior.

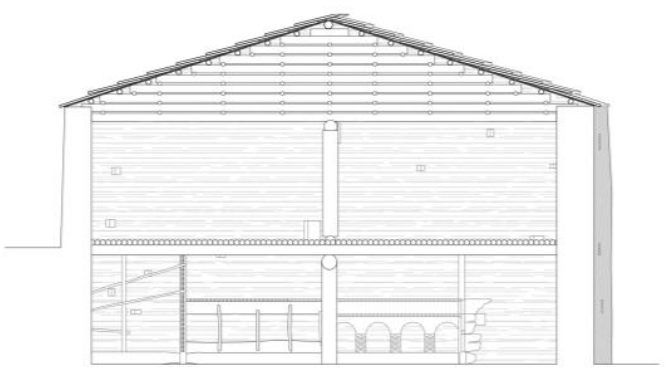

Figure 4. Section of Machubi 10, Chazhashi, Ushguli, CI-ESG, 2019.

The darbazi is the upper floor of the house, and has an open plan, with no partitions. In winter it serves as a haystack, but in the mild summers, it is occupied by the family. In this level, a door connects to a wooden passage (gubandi) that gives access to the tower. For defensive reasons, the entrance of the tower is elevated and the only connection is this wooden structure that can be easily destroyed in case of an attack.

The furniture is scarce, reflecting both the frugality of life in the mountain, and the need to move from the machubi to the darbazi and back. It is composed of a few wooden stools dispersed around the fire and a more elaborate raisen plataform with skins and cuchions, also made of wood, that serves as a family couch. 


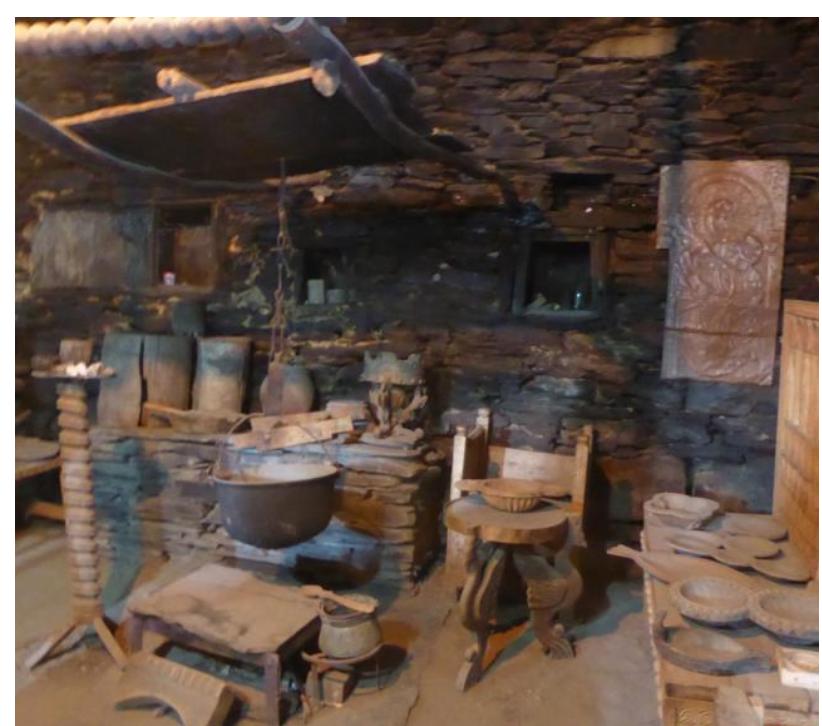

Figure 5. Inside of a Machubi, Zhibiani, Ushguli, CI-ESG, 2018

\section{LIVED AND CONCEPTUALIZED SPACE}

Finally, the lived and conceptualized space is addressed, bringing forward the gender-differentiated symbolic use of the domestic space.

As detailed above, the machub is composed of a single space with a central fireplace. This element is the axis of the spatial organization of the house, and therefore of the segmentation of female and male symbolic spaces inside the house.

The fireplace outlines two separate ritual spaces, the right side of the eastern facade, where the window of prayers or window of offerings is placed, constitutes the male symbolic domain. The women, on the other hand, ritual and symbolically control the space around the fireplace and by the left side of the western façade, where the meals are prepared and food is stored.

Another peculiar trace, that reinforces the connection of the Svan women`s sacred geography and the domestic interior, is the existence of a domestic spirit (mezir) to whom they are devoted, alongside with the Virgin Mary and St. Barbara (Tserediani et al., 2018).

Inside the house, around the fire, is where the main female prayers and rituals take place, while the men, although preserving some symbolic control inside the house, choose public spaces, such as churches, churchyards and cemeteries as their principal ritual grounds. This ritual use of public space is severely restricted for women who cannot enter churches. Nevertheless, feminine sacred geography is very rich in Upper Svaneti.

Some ceremonies, such as ritual bread baking, take place in the lamaria, a space attached to the church, built specifically for this purpose, but that, on specific dates of the liturgical calendar, is also used for female communal prayers. Other feminine rituals take place in the outskirts of the villages, perpetuating the sacred geography inherited from ancient times.

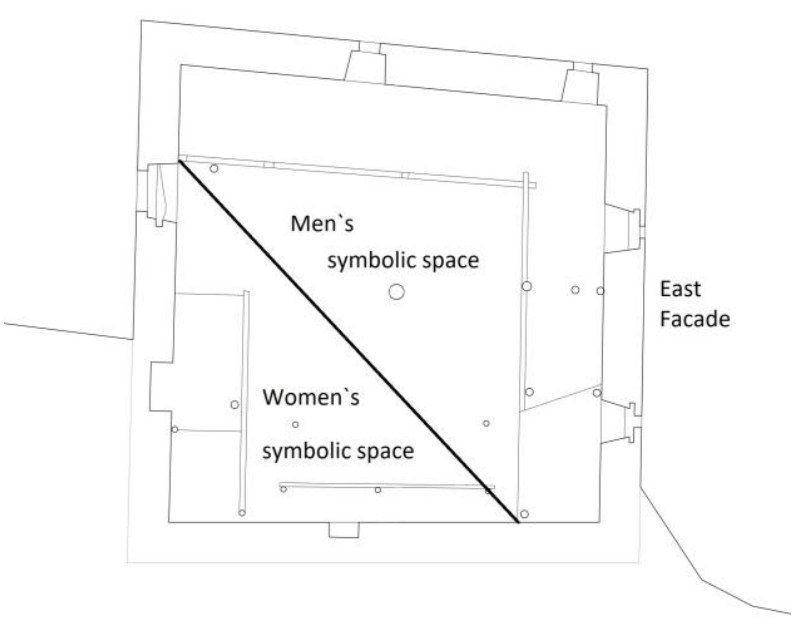

Figure 6. Symbolic use of Machubi 10, Chazhashi, Ushguli, based on Chartolani, 1961, p. 13.

As Tuite (2019) describes for the Bronze Age, the Svan men still choose public spaces for their ritual activities while the women pick the Interior of the Interior and the Exterior of the Exterior.

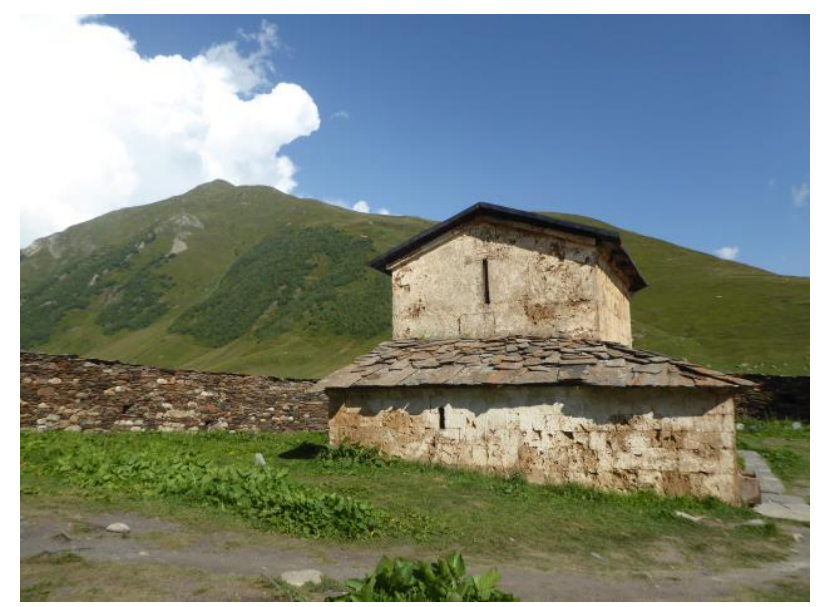

Figure 7. Lamaria at St. Georges Church, Zhibiani, Upper Svaneti, CI-ESG, 2018.

Tserediani, Tuite e Bukhrashvili (2018) explain the ritual segregation of the domestic interior with some similarities with the church's organization. In both spaces there are sanctuaries (t'arbez), a place for preparing meals and land plots. The orthodox churches at Upper Svaneti were also built in the Georgian Golden Age, and respond to the implementation of a feudal system, where the noble families also appropriated the religious space. Therefore, they have to be understood as family chapels, which explains their reduced space (around 20 to 50 $\mathrm{m} 2$ ). Their plan is also very simple, with one aisle and an apse in the eastern façade. This is where the tarbez, also known as the Eastern Window, is located. The lamaria is usually in the south façade. Connected to the religious building there were traditionally plots of land, where they grew the cereal later used in the baking of ritual bread. 


\section{CONCLUSION}

This paper was developed under the $3 \mathrm{D}$ project and aimed at the interpretation of the different uses of space in the vernacular house of Upper Svaneti, from a historical and anthropological perspective. In order to achieve this goal, the vernacular architecture of Upper Svaneti was studied so that the connections between the built environment and the immaterial culture of the Svan could be established.

According to the above-mentioned Foucault's theory, space is a series of connections that affect our daily life. This everyday life is filled with ideologies, some hegemonic and others marginal. Some, mainly the former, are unnoticed by the users themselves, as they have become naturalized. Therefore, space is a cultural construction established and controlled by a community that shares a worldview, their vision of reality.

The house is one of these spaces generated by the community's worldview and one where it is better represented, in such a way that its symbolic analysis allows us to understand the ideology that has generated it.

Houses are a key repository of the biographies and cultural memory of the communities inhabiting these territories, since they work as outstanding elements in shaping personal, family and communal identities (González-Álvarez, Alonso, 2019). Conventional places, that is, spaces settled for daily tasks, such as a house, comprise the definition of limits of action, as well as the position and disposition that must be maintained in them. This can be clearly recognized in the symbolic use of the house in Upper Svaneti, where some spaces, such as the fireplace or the eastern façade, have deserved particular attention for their role as the symbolic centres of the house.

Through the house, one can understand the relationships that are established and the influence that this particular way of building the social space has on the way of conceiving and living in the dwelling. In Upper Svaneti it shows how ritual configuration of the domestic space preserves a dichotomous and oppositional ideology in terms of genders.

But there are other spaces that perpetuate the same dichotomous worldview, those comprise what Foucault (2008) names heterotopies: spaces built in front of the conventional places or in parallel, but that escape normality, conventionality, and everyday life. Usually closed spaces guarantee some privacy (Valverde, 2009). Here in Upper Svaneti the heterotopy is represented by the church, forbidden places that are reserved for men.

In conclusion, one can establish two main ideas from the symbolic analysis of the vernacular house of Upper Svaneti. The first highlights a dichotomous worldview concerning gender and space. The second concerns a peculiarity of the former, namely, the connection between religious/domestic space.

In Upper Svaneti, gender dichotomy goes back to the preChristian religion, possibly dating from the Bronze Age, when deities were conceived as pairs, as a representation of other dualities: masculine/feminine, pure/impure, interior/exterior. This is still visible in the way Svan men choose masculine deities as their protectors, while women choose female saints. It is one of the many pre-Christian religious traces that survived in Svan`s popular Christianity, as well as the duality of spaces associated - Interior/Exterior.
While during the Georgian Golden Age, Upper Svaneti saw both the consolidation of Orthodox Christianity and the appropriation of religious spaces inside the villages by local noble clans, pagan beliefs and rites were perpetuated by peasants in the secrecy of their homes, or in discreet spaces on the periphery of villages; spaces that since ancient times were symbolically associated with women. Thus, establishing a new duality between official and private religious spaces.

After the Ottoman conquest, the importance of orthodox clergy was visibly weakened in all Georgian territory, but, in Upper Svaneti, it came to a point where they were completely excluded. From this moment on, the elders took up the role of religious leaders, promoting the confluence of both public and private, Christian and pagan religious practices. One dual aspect of the former system was although preserved: the space dichotomy between religious and domestic spaces.

Now that the ancient rites, presided by the elders were once more practiced in public spaces, the dichotomy between religious and domestic spaces was a form of gender segregation, keeping women out of the public religious spaces. Contrary to the dycothomy public/private spaces, in what concerns public rituals and ceremonies, one can observe some similarities in the symbolic use of religious and domestic spaces. The reason for this aparent contracdiction is simple: women, relegated to secondary roles in public rituals and ceremonies, use domestic interior as their primary ceremonial space.

The fireplace, associated with the preparation of meals, a chore traditionally attributed to women, is the key element in the ritual segregation of the domestic space, but it is also present in the religious buildings, where the lamaria attached to the church allows access to women, in order to bake ritual bread. This can be interpreted as a feature copied from the vernacular house to the religious building.

The reverse is also visible, in this case, the tarbez, or eastern window, the sancto sanctorum of the Svan Orthodox church, is symbolically represented in the vernacular house by the eastern façade, thus serving as the second key element in the delimitation of masculine and feminine spaces inside the house.

\section{REFERENCES}

Berman, M., Kalandadze, K., Kuparadze, G., Rusieshvili, M., 2011: Georgia through its legends, folklore and people. Nova Science, New York.

Chartolani, M. 1961. From the History of the Material Culture of the Georgian People. Mecniereba, Tbilisi.

Duch, L., 2002: Simbolismo y Salud (Antropología de la vida cotidiana). Trotta, Madrid.

Durkheim, E., 1968: Las formas elementales de la vida religiosa (1912). Colofón/Premia, México.

Foucault, M., 2008: Of other spaces. Heterotopia and the City, Routledge, London, p. 25-42.

Freshfield, D., 1896: The exploration of the Caucasus. Edward Arnold, London. 
González-Álvarez, D., González, P. A., 2019. Houses and Cultural Change: An Interdisciplinary Methodology for the Exploration of the Built Environment in Contemporary Rural Spain. Arqueología de la Arquitectura, 16, e085.

Tserediani, N., Tuite, K., Bukhrashvili, P., 2018. Women as Bread-Bakers and Ritual-Makers. Sacred places, Emerging spaces: religious pluralism in the Post-Soviet Caucasus. Berghahn Books, New York, p. 46-69.

Tuite, K., 2002. Real and imagined feudalism in highland Georgia. Amirami, 7, 25-43.

Valverde, R. R. H. F., 2009. Sobre espaço público e heterotopia. Geosul, 24(48), p. 7-26. 